\title{
Research on the Ningxia Economic Development Model from the Perspective of Industry Cluster
}

\author{
Jianzhong Li \\ Yinchuan Municipal Office, \\ Yinchuan,Ningxia, 750011 China
}

\begin{abstract}
In this paper, we conduct research on the Ningxia economic development model from the general perspective of the industry cluster. The enthusiasm of developing industrial cluster in China in recent years, governments at all levels to include cultivating industrial cluster in the area or industry development plan, with the industrial clusters of our country the influence of the national economy is increasing day by day. Fierce in the current economic situation, to promote our country independent innovation ability of industrial clusters and knowledge update speed, promote the transformation and upgrading of industrial cluster has become the fundamental guarantee for maintaining international competitiveness of industry cluster in our country. Our research proposes the novel perspective of the developmental trend of Ningxia economy that holds special meaning.
\end{abstract}

Keywords- Economic Development, Industry Cluster, Perspective, Ningxia Characteristics.

\section{Introduction}

Production activities is one of the most basic activities of national economy, in the process of social reproduction, production is the primary link and important foundation that created the value of the production activities and results, namely, gross domestic product, in the core economic cycle system allocation, use and so on the basis of each link. In other words, logical and perfect the system of the national economic accounting is closely around the production activities and results of using layer upon layer. Based on gross domestic product and the analysis and research of the income distribution and end use, not only can the total scale of comprehensive understanding of economic development, the overall grasp the operation of the national economy, but also can reflect the production results in the allocation and use of the link structure, reveal a significant percentage of the national economy relation, thus to provide scientific decision basis for economic development strategy [1-3].

As is located in the northwest region of Ningxia autonomous region in the western development strategy under the guidance of society with the rapid economic development, but also faced with the severe employment pressure at the same time, there are mainly caused by the structural adjustment of a large number of laid-off workers, due to the urbanization process to speed up a large number of the transferring rural surplus labor force, and a new labor which is formed by the peak due to population growth, and university students' employment pressure. The employment situation of Ningxia has a clear, comprehensive control, and puts forward some suggestions for the existing problems to solve the employment problem in Ningxia and measures taken for their future provides valuable reference.

The construction of a harmonious society requires a new regional interest coordination mechanism. In this mechanism, establish a new regional and global interest distribution variation relationship by encouraging each region to strive for the region's economic interests and to maximize the economic interests of overall implementation. The benefit sharing mechanism, which requires implementation "advantage, development characteristics and common 
growth," the new pattern of regional economy. In such a new pattern, each region to find suitable for their own development direction, so that the whole social and the economic life in a new kind of the balance and harmony. Support the Midwest technology progress of the development of characteristic industry, basic industries and from poverty and becoming rich, and through the economic lever to adjust and policy guidance makes the Midwest resources transformation strategy and speed up the basic development strategy of the country's east, connected, organic combination, to communication by the traditional administrative region division of the economic relations, speed up the development of the underdeveloped areas and promote the leap-forward development of underdeveloped regions, on the basis of the organic combination of the formation of mutual promotion and common development between regions of regional structure, the northeast old industrial base transformation, western development, giving full play to the advantages of the central region comprehensive conditional area in the east as the first modern together into the overall national economy coordinated development system.

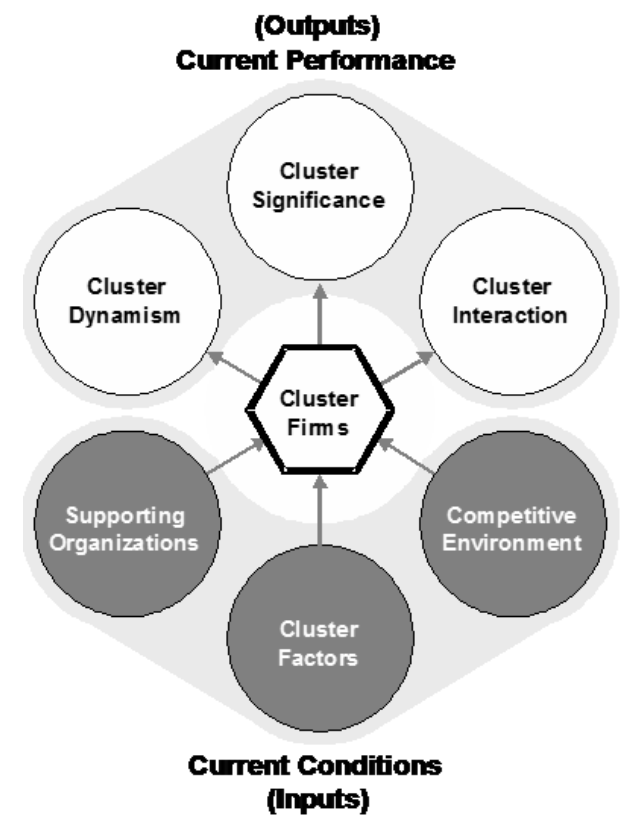

Figure 1. The General Components of the Industry Cluster Pattern
In this paper, we conduct research on the Ningxia economic development model from the general perspective of the industry cluster. Industrial clusters gradually evolved into a worldwide economic phenomenon as an important characteristic of modern industrial development. Industrial clusters, as a kind of to create competitive advantage and formation of the industrial spatial organization form, it has a group in the development of competitive advantage and agglomeration economies of scale is unmatched by other forms. Innovation is the future of the industry cluster and innovation is the power of industrial cluster upgrading, industrial cluster in innovation. Innovation is an important source of industrial cluster competitiveness of modern industrial clusters innovation ability is always support the decision of the sustainable development of industrial cluster.

\section{The Proposed Methodology}

The Economic Development Pattern. At present, the development of the macro economy appeared many new characteristics, the central region has already entered the stage of rise, from the national development and change of the pattern of the macro requirement and situation of the central region, central region cannot copy export-oriented development pattern on the east coast, that must explore endogenous type and extroversion, combining with endogenous model give priority to development of the model. Endogenous development pattern refers to rely mainly on domestic market, domestic resources, domestic technology and the developing mode of domestic capital, on this basis, the central region to the organic combination of the endogenous development and export-oriented development, formed the development pattern of the central features, achieve finally and coastal export-oriented complementary and interactive mode to change the way of promote the development of the country. 
Accordingly, we should be based on listed suggestions. (1) Recycling principle. Reuse principle refers to items used by as many times as well as many ways as possible to primary reduce resource consumption and pollution emission. (2) Recycling principle. It is to make full use of waste resources recycling, and waste that can reduce the pressure on landfills and incinerators. See from the running principle of circular economy, reduction principle of energy saving method, aimed at reducing into the physical quality of the production and consumption process. (3) Reduction principle. Reduction principle is to point to by redesigning the production process or transformation of the ways to reduce consumption idea and so on into the physical quality of the production and consumption process. In production can be in the process of producing by reducing the material consumption of each product, through to design and manufacture process to save resources and reduce pollution emission.

The Industry Cluster. So-called industrial upgrading, it is to point to in certain domestic and the international economic environment and the resource conditions, according to the general law of the evolution of industrial structure and the inherent requirement of industry development, take certain measures to constantly improve the industrial structure and the development level, ensure national economy to long-term sustained growth of a kind of economic activity [4-5].

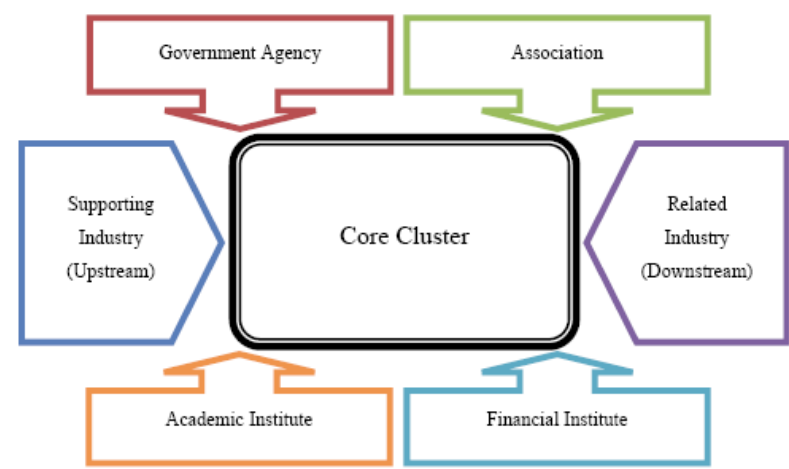

Figure 2. The Industry Cluster Demonstration

Look from effect, industry population attribute refers to a kind of population and industry internal conditions and the external environment related properties. It can be divided into effective industry population and inefficient industry two kinds. (1) Effective industry refers to the population within a certain area that has its industrial properties that meet the needs of internal conditions and external environment, and has the relative advantage of industry group. (2) If the industry the number of each element in the population, distribution density and the structure is unreasonable, or repel each other, and relationship between each factor disorder; Change or is it because of the external environment, internal and external conditions not harmonious as the populations of industry is invalid.

Specifically, small enterprise cluster is a group of independent but interrelated small business on the basis of professional division of labor and cooperation established organization, the organization structure between pure market and primary hierarchy organization, it is market is stable, flexible than hierarchical organization. With the aid of this special organization structure, to establish long-term trade relations between small businesses do not necessarily need to contract to maintain, and mainly to collaborate through trust and commitment. Therefore, each of the small businesses can get within a cluster to cluster outside the enterprises have no competitive advantage. Social network theory, new classical economics and basic new institutional economics research only physical capital and human capital, and ignores the role of social capital for the development of the economy.

The so-called social capital is a kind of intangible social resources, or trust is through the social and economic system formed by the basic interaction of the "capital". It may exist in social networks, by recognizing some of key figures or have certain influence to obtain specific resources and assistance as it may also exist in the social contract, it may even exist in an invisible social trust relationship. Economic 
organization is based on the formal contract of economic relations, social organizations of social relations is based on informal contract. Produce connection of social capital can be generated at the individual level and organizational level, although they often can be attributed to the relevant individual behavior. These links may be directly and indirectly, that might change their strength, and output depends on the network class [6].

The Features of Regional Economy. Before the theory of basic unbalanced growth of regional economy, the new classical economics theory of the regional economic balanced growth has been in a dominant position. Growth of new classical economics theory, regional long-term growth depends on the three elements of capital, labor and technology progress, because under the basic condition of free competition, labor is always flow from low wage regional to higher wages that capital is always flow from higher wages regional to low wages. Regional economic policy, government regulation is one of the important methods of regional economic development and operation. Because of the different regional resources endowment and market decisions and the government regulation is not perfectly competitive, in the pure law of market value function or under government macroeconomic regulation and control and it is difficult to realize the optimization of regional resources configuration and the optimal overall regional development. Therefore, how to make scientific, rationalization of regional economic policymaking is one of the main scientific problems facing regional development research.

The traditional economic growth theory is that capital accumulation, and technological progress to improve the quality of labor increase or factors is the key to economic growth, economic growth has slowed and the less developed countries or regions due to the lack of the above factors. Such as Solow model, Romer and Lucas model technology as the key to economic growth, regardless of institutional factors, in fact, the economy is the institutional factor and decisive. New institutional economics argues that economic growth is the institutional factors and the non-technical factors and decisive, emphasizes the institutional analysis in economics should be the core status, think efficient economic organization is the key to economic growth, institutional change decided to technological change [7].

The Ningxia's Economy. Industrialized country is a transformation from traditional agricultural civilization to modern industrial civilization, the process of it is any country modernization inevitable stage. The party's 16th national congress explicitly put forward industrial development to take a new road to industrialization, Ningxia has to take a new road to industrialization as the important measures to accelerate the rapid and fast industrialization of Ningxia mentioned a strategic height. To promote industrialization, especially the new industrialization is narrowing the gap with advanced areas in Ningxia, achieve the strategic change economic growth mode, the inevitable requirement of winning advantage in the western development; Also improve the level of economic development in Ningxia, get rid of the long-term fiscal constraints problem in the Ningxia, fundamentally ease the increasing employment pressure to promote urbanization necessarily smoothly [8].

With the deepening of the reform and opening up and the effective implementation of the western development policy, Ningxia has a huge economic and social development and the change, but after Ningxia as a development area, due to historical conditions, natural environment and geographical conditions, which have a relatively level of productivity, economic output is small, comprehensive strength is poor, weak the material foundation of building a harmonious society, is still faced with the reform and development lags behind. At the same time, as a national region in Ningxia, to solve the contradictory between ethnic and religious, to 
ensure that the task of social stability is also very heavy. Therefore, under the new situation and requirements, Ningxia government entities at all levels must raise awareness, based on reality, innovative ideas, accelerate the construction of the government administrative ability, give full play to the government macroeconomic regulation and control and the management service of economic and social role, build environment which provide power for the construction of a harmonious Ningxia. Building the harmonious socialist society, is essentially social contradictions constantly adjusted a practice and historical process. Due to differences in level of the productivity development and the social development degree, the major form of different parts of the social contradictions of each different with the degree and level of building a harmonious society is different that also have different requirements and priorities.

\section{Conclusion}

In this paper, we conduct research on the Ningxia economic development model from the general perspective of the industry cluster. Innovation is an important and basic source of industrial clusters competitiveness. Generally speaking, industrial cluster effect on innovation are mainly concentrated in four aspects: provide enterprises with a good innovation atmosphere, reduce the cost of enterprise innovation, is advantgeous to the enterprise technology innovation support network formation, and promote the transfer of knowledge and technology diffusion. Industrial cluster innovation source of power demand in market, intermediary organizations, government support, science and technology, competition between enterprises with the collective learning mechanism, the innovation culture and the values of the effective incentive, etc. Symbiosis can produce a large number of surplus so that the cluster innovation network participants gain the benefits of the cooperation and enhances their own strength, thus obtain the competitor cannot get outside the cluster innovation advantage. In the future, more corresponding research will be introduced.

\section{References}

[1] $\mathrm{Hu}, \mathrm{Xiao}-g u a n g$, and Xu Cai. "The analysis of the institutional barriers in the cluster developments of the equipment manufacturing industry." Information Management, Innovation Management and Industrial Engineering (ICIII), 2013 6th International Conference on. Vol. 3. IEEE, 2013.

[2] Zhang, Jian, Nan Wang, and Jie Hong. "Comprehensive Evaluation on the Development of Industry Cluster Circular Economy." Advanced Materials Research. Vol. 779. 2013.

[3] Dang, Chenyang, and Jiaqiang Mao. "Based on industrial cluster competitiveness evaluation of high-tech zone-Case study of Xi'an High-tech Zone." Information Management, Innovation Management and Industrial Engineering (ICIII), 2013 6th International Conference on. Vol. 3. IEEE, 2013.

[4] Yu, L. U. O. "A Review on Agriculture Industry Cluster." Journal of Anhui Agricultural Sciences 9 (2012): 041.

[5] Roy, Rupam. "“Entrepreneurship Evolution of Cluster Industry in Assam" with special emphasis to Bell metal Industry of Sarthebari." (2014).

[6] Chen, Feng Ping. "Hebei Home Textile Industry Cluster Optimization Research Based on SWOT Analysis of Entropy Fuzzy Comprehensive Evaluation." Advanced Materials Research. Vol. 627. Trans Tech Publications, 2012.

[7] Hamilton, Virginia. "Career pathway and cluster skill development: Promising models 
from the United States." OECD Local Economic and Employment Development (LEED) Working Papers 14 (2012): 0_1.

[8] Jia, Xiaohui, Minghui Jiang, and Tao Ma. "The dynamic impact of industrial cluster life cycle on regional innovation capacity." Economic

Research-Ekonomska Istraživanja 28.1 (2015): 807-829. 